\title{
Stings of the missing string: missing Copper T thread
}

\author{
Ketaki K. Junnare ${ }^{1 *}$, Saloni Savaskar ${ }^{2}$, G. S. Shekhawat ${ }^{1}$ \\ ${ }^{1}$ Department of Obstetrics and Gynecology, Smt. Kashibai Navle Medical college and General Hospital, Pune, \\ Maharashtra, India \\ ${ }^{2}$ Department of Obstetrics and Gynecology, Dr. Vaishampayan Memorial Government College, Solapur, Maharashtra, \\ India
}

Received: 30 August 2019

Revised: 19 November 2019

Accepted: 28 November 2019

\section{*Correspondence:}

Dr. Ketaki K. Junnare,

E-mail: ketaki.junnare@yahoo.com

Copyright: ( $)$ the author(s), publisher and licensee Medip Academy. This is an open-access article distributed under the terms of the Creative Commons Attribution Non-Commercial License, which permits unrestricted non-commercial use, distribution, and reproduction in any medium, provided the original work is properly cited.

\section{ABSTRACT}

Background: Missing CuT thread is a worrisome complaint for a woman. The string may be curled in or the $\mathrm{Cu} \mathrm{T}$ might have expelled or migrated.

Methods: It was a retrospective study. Authors collected the data between January 2017 to December 2017. Data was collected from OPD, OT register and Indoor patient record file. The objective was to ascertain the symptomatology, type of insertion, investigations and mode of retrieval of $\mathrm{CuT}$.

Results: There were 63 cases of missing CuT thread, out of which, 42 were postpartum. 33 patients were asymptomatic. Irregular vaginal bleeding (19 patients) was commonest complaint, followed by abdominal pain (10 patients). Pregnancy was detected in one patient. Transvaginal ultrasonography (TVS) detected intrauterine location of $\mathrm{CuT}$ in 60 cases. X-ray abdomen erect was needed in 3 cases, which detected intra-abdominal migration of $\mathrm{CuT}$ in two cases. CuT was expelled in third case. In 31 patients, CuT was removed by artery forceps in OPD. In 17 cases, hysteroscopic Copper T removal was needed. Two cases with migrated $\mathrm{CuT}$ underwent laparoscopy for retrieval of $\mathrm{CuT}$. One patient had to be converted to laparotomy to rule out bowel injury.

Conclusions: Missing CuT thread is commonest with postpartum IUCD. TVS should be first investigation in missing $\mathrm{CuT}$ thread. X-ray abdomen is needed only if CuT is not visualized on TVS. Hysteroscopy can be used in patients where CuT retrieval with artery forceps fails. Laparoscopy and laparotomy may be required in migrated CuT cases.

Keywords: Hysteroscopic removal, Laparoscopy, Laparotomy, Missing CuT thread, Transvaginal ultrasonography, X-ray abdomen

\section{INTRODUCTION}

Intra-uterine contraceptive device (IUCD) is the most commonly used form of reversible contraceptive with an estimate of 150 million women using it worldwide, be it Copper containing intrauterine devices or hormonal intrauterine system (IUSs) in 2007. ${ }^{1,2}$ Women can opt for its removal according to their convenience and removal of Cooper $\mathrm{T}$ is nothing but a simple method requiring grasping and pulling out of the visible string, firmly but gently. 3,4

But what when the patient comes to you with complains of missing CuT thread? As many as $4.5-18.1 \%$ users have missing threads either on string checks or at the time of removal. ${ }^{3,5,6} \mathrm{~A}$ number of studies have shown that the majority of IUCDs with missing threads can be dealt with in the office as a minor procedure with the use of appropriate tools. 
Rarely, missing IUCD thread can be due to migration of IUCDs also. A very rare but potentially life-threatening complication of IUCD use is Uterine perforation, with an incidence of 0.12 to 0.68 per 1000 insertions. ${ }^{7}$ The patient may remain asymptomatic for varying amount of time or may present with pregnancy or 'missing strings. A small number of people present with features of acute abdomen like bowel obstruction or perforation., ${ }^{8,9}$

\section{Objectives of this study were}

- To ascertain the type of insertion of IUCD which present with missing string

- To assess the associated symptoms

- To assess the investigations required to locate the IUCD

- To study the mode of removal of missing IUCD.

\section{METHODS}

This is a retrospective study, carried out in Smt. Kashibai Navale Medical College, Pune, Maharashtra, India. The data was collected in the interval from January 2017 to December 2017.

\section{Inclusion criteria}

- All patients who came with complains of missing IUCD thread during January 2017 to December 2017 were included in the study.

\section{Exclusion criteria}

- Patients who were lost to follow up were excluded from the study.

Records of patients were studied between January 2017 to December 2017. Data was collected from OPD register, Indoor patient record file and OT register.

A record of type of IUCD insertion (postpartum / interval or post-abortal) was made. The symptoms of patients were analysed. In all patient's pregnancy was ruled out and tests were done for locating the IUCD. The patients who requested for $\mathrm{CuT}$ removal; methods used for $\mathrm{CuT}$ removal were studied. The details were noted from OT record sheet wherever needed.

\section{Statistical analysis}

The data was collected, compiled and tabulated with help of Microsoft excel 2010. Analysis was done with the help of Epilnfo software in terms of rates and proportions.

\section{RESULTS}

There were sixty-three cases reported with missing IUCD thread in the study period.
Table 1: Age of patients.

\begin{tabular}{|lll|}
\hline Age & Number & Percentage \\
\hline $20-25$ & 22 & 34.96 \\
\hline $26-30$ & 29 & 46.03 \\
\hline $31-35$ & 10 & 15.87 \\
\hline$>36$ & 2 & 3.17 \\
\hline
\end{tabular}

Authors studied the demographic distribution of the patients and found that the most common age group was 26-30 years which was about $46.03 \%$ (Table 1 ). As many as $61.90 \%$ of patients were primi parous (Table 2).

Table 2: Parity of patients.

\begin{tabular}{|lll|}
\hline $\begin{array}{l}\text { Number of living } \\
\text { children }\end{array}$ & $\begin{array}{l}\text { Number of } \\
\text { patients }\end{array}$ & Percentage \\
\hline 1 & 39 & 61.90 \\
\hline 2 & 21 & 33.33 \\
\hline 3 & 3 & 4.76 \\
\hline 4 & 0 & 0 \\
\hline
\end{tabular}

The most common type of insertion of Cooper $\mathrm{T}$ was post-partum which accounted for $42(66.66 \%)$ cases, of which 33 were inserted during LSCS and the remaining 09 were inserted after normal vaginal delivery. Interval $\mathrm{CuT}$ insertion was done in $12(19.04 \%)$ cases while postabortal CuT insertions were done in $14.28 \%$ cases ( 9 cases) (Table 3).

Table 3: Type of insertion of CuT.

\begin{tabular}{|lll|}
\hline Type of insertion & Number & Percentage \\
\hline Interval & 12 & 19.04 \\
\hline Postpartum & 42 & 66.66 \\
\hline Vaginal & 09 & 14.28 \\
\hline LSCS & 33 & 52.38 \\
\hline Poastabortal & 09 & 14.28 \\
\hline Total & $\mathbf{6 3}$ & \\
\hline
\end{tabular}

Table 4: Symptomatology.

\begin{tabular}{|lll|}
\hline Complaint & Number & Percentage \\
\hline Asymptomatic & 33 & 52.38 \\
\hline Bleeding & 19 & 30.15 \\
\hline Pain in abdomen & 10 & 15.87 \\
\hline Pregnancy & 01 & 1.58 \\
\hline Total & $\mathbf{6 3}$ & \\
\hline
\end{tabular}

When authors assessed if the patient had any associated symptoms, it was found that maximum cases (33 patient, $52.38 \%$ ) had no associated complains except for complains of missing CuT thread. This was followed by complains of irregular per vaginal bleeding in $30.15 \%$ (19 patients) cases. Pain in abdomen was the next common symptom which was present in 10 cases $(15.87 \%)$. It was the major complaint in both the patients 
who had intraperitoneal CuT. One out of 63 cases had an 8 weeks pregnancy with Cooper $\mathrm{T}$ in situ (Table 4).

Patients presenting with absent Cooper T string were first subjected to Transvaginal sonography (TVS). If Cooper T was seen on TVS, Cooper T removal was attempted using simple artery forceps in OPD. If that failed, patient was posted for hysteroscopy and Cooper $\mathrm{T}$ was retrieved by hysteroscopic method.

If, however, Cooper $\mathrm{T}$ was not visible on TVS, the patient was subjected to X-ray abdomen erect. Thus, Xray pelvis was not the first investigation in this study.

Table 5: Investigations.

\begin{tabular}{|ll|}
\hline Investigations & Number \\
\hline Trans vaginal ultrasonography (TVS) & 60 \\
\hline TVS and X-ray abdomen & 3 \\
\hline Total & $\mathbf{6 3}$ \\
\hline
\end{tabular}

In this study, out of 63 cases, 60 patients underwent only TVS $(95.23 \%)$ and it was found that all of them had Intra-uterine Cooper Ts. Only 3 cases $(4.76 \%)$ had to be subjected to X-ray abdomen erect (Table 5), out of which it was seen that 2 cases had abdominal migration of Cooper $\mathrm{T}$ while in one patient, the device was not visible even on X-ray, suggesting an expelled Cooper T.

Table 6: Mode of CuT removal.

\begin{tabular}{|ll|}
\hline Mode of CuT removal & Number \\
\hline With artery forceps & 31 \\
\hline Hysteroscopic removal & 17 \\
\hline Laparoscopic removal & 1 \\
\hline Laparotomy & 1 \\
\hline
\end{tabular}

Out of the sixty-three patients, twelve from intracaesarean post-placental $\mathrm{CuT}$ insertion group opted for continuation of the CuT. They were advised to follow up in OPD after six months.

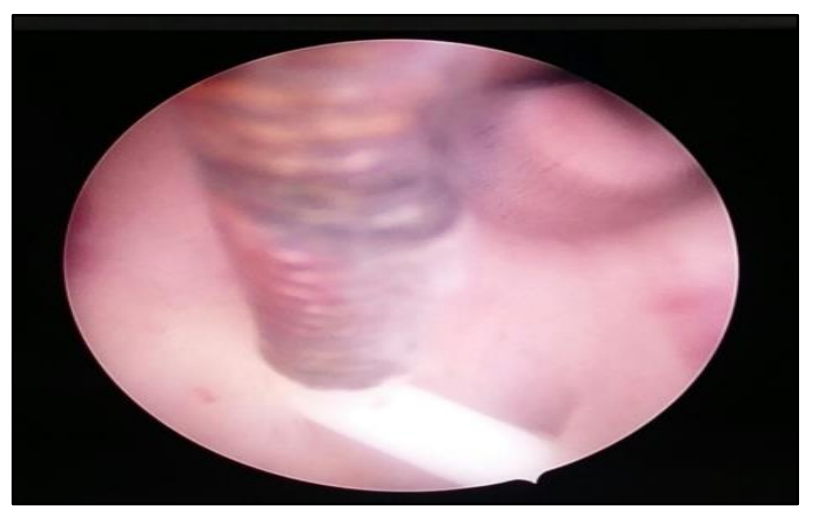

Figure 1: Hysteroscopic CuT removal.

The patients, who requested for CuT removal, underwent $\mathrm{CuT}$ removal in OPD using an artery forceps. $31 \mathrm{CuT}$ were successfully removed by this simple method only. In the rest 17 cases, hysteroscopic Cooper T removal was done as shown in Table 6 (Figure 1).

Twelve patients with missing thread chose to continue with $\mathrm{CuT}$ and were advised to follow up six monthly for TVS.

The two cases, in which Cooper T was not seen on TVS but was found in X-ray Abdomen Erect, underwent diagnostic hystero-laparoscopy.

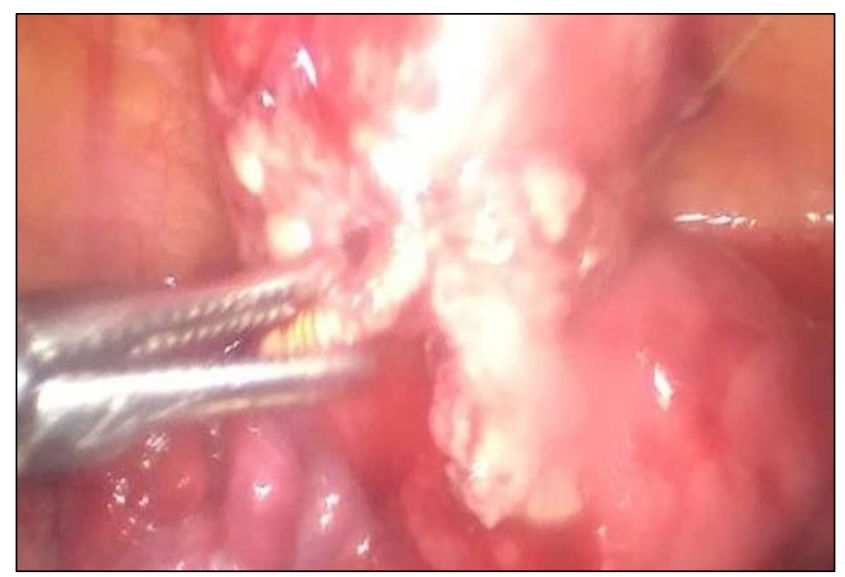

Figure 2: Laparoscopic CuT retrieval (Case 1).

Case 1

CuT was not seen on hysteroscopic examination. Diagnostic laparoscopy was performed. CuT was seen adherent to the anterior abdominal wall, entangled in omentum, which was removed laparoscopically after adhesiolysis (Figure 2).

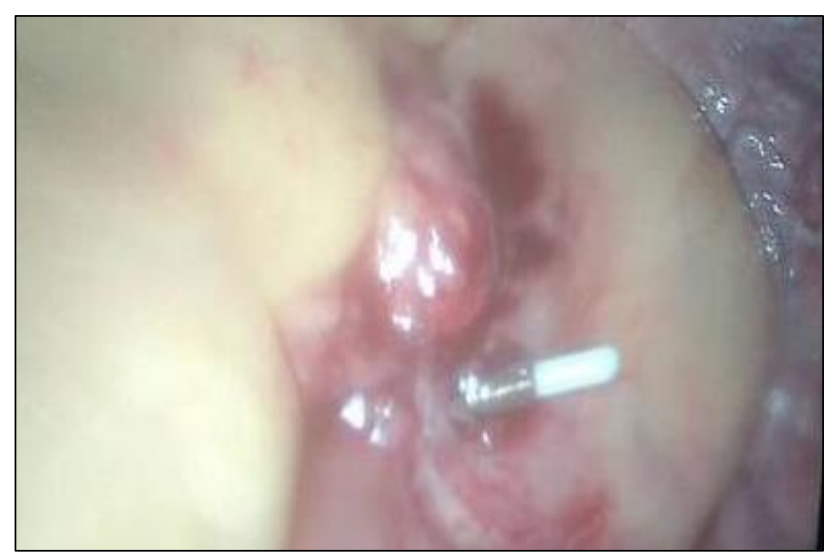

Figure 3: CuT entangled in bowel and omental mass (Case 2).

Case 2

CuT was not seen on hysteroscopy. A diagnostic laparoscopy was done and CuT was seen in the mass involving omentum and bowel. CuT was removed with a 
grasper but to confirm bowel integrity, laparotomy was performed (Figure 3).

The patients had a normal post-operative recovery. Both the intra-abdominal migrated Copper $\mathrm{T}$ were inserted post-abortal.

\section{DISCUSSION}

PPIUCD was the commonest type of IUCD where missing string was the complaint. Mishra S et al, has stated that missing strings after PPIUCD insertion is a pertinent problem encountered during PPIUCD followups. $^{10}$

In this study, transvaginal ultrasound was the first investigation done in patients with missing CuT thread. On ultrasound, the IUCD should have a double bar sign and create shadowing. A study conducted by Elahi $\mathrm{N}$ et al, also used ultrasound as the primary modality of investigation. ${ }^{11}$ Ultrasound is usually the first choice of investigation for determining intrauterine position due to its cost effectiveness, lack of ionizing radiation and greater detail of pelvic anatomy. ${ }^{12}$ A study conducted by Marchi NM et al, et al also concluded that ultrasound confirms the position of Cooper T. ${ }^{13}$

If intrauterine placement is doubtful, further imaging to establish its placement must be performed. X-ray Abdomen Erect with uterine sound in situ will help us with the position of CuT. Positioning on an abdominal radiograph varies with normal uterine positions but the IUD should be located near midline low in the pelvis and oriented with arms superior to the stem. ${ }^{12}$ In cases where complications like perforations are suspected, computed tomography (CT) or magnetic resonance imaging (MRI) may be helpful. Of note, both Cooper $\mathrm{T}$ and hormonereleasing devices are considered safe for up to 3-T MRI. ${ }^{14}$

If intrauterine IUCD is confirmed and the patient wishes to continue IUCD, no further investigations are needed. The patient is however asked to keep a follow up every 6 months and asked to visit when she misses her period to rule out pregnancy and thus, expulsion.

In patients who desire IUCD removal, it can be removed as an office procedure with the use of artery forceps. Instruments like IUD extraction hook, alligator forceps, Emmett IUD thread retriever, Mi-Mark helix and Retrievette IUD thread retriever have also been described. ${ }^{10}$ Hook devices and suction curettes are more often successful in retrieving rings or loops, while grasping devices are more useful for T shaped devices. ${ }^{15}$ But as none of the office retrievers are available with us, authors used simple artery forceps to remove these intrauterine IUCD. A study conducted by Mishra S, et al, who studied about missing PPIUCD (post-partum intrauterine contraceptive device) threads also used artery forceps for the removal of Cooper $\mathrm{T} .{ }^{10}$ In this study majority of the missing CuTs were removed as office procedure similar to findings seen in study conducted by Prabhakaran S and Chuang A. ${ }^{15}$

Hysteroscopic CuT removal was done in patients in whom it could not be removed in OPD. It gives us the advantage of removing Cooper $\mathrm{T}$ under vision. Hysteroscopic removal is required in cases of embedded Cooper T. ${ }^{12}$

When intraperitoneal migration of $\mathrm{CuT}$ was suspected, authors proceeded with diagnostic laparoscopy. In case 1, $\mathrm{CuT}$ was found adherent to anterior abdominal wall and entangled with omentum. Authors successfully retrieved the $\mathrm{CuT}$ with the help of a grasper after adequate adhesiolysis. Sterile pus was also drained from the mass. In case 2, the CuT was seen en mass with omentum and colon. Authors retrieved the $\mathrm{CuT}$ with the help of a grasper but were doubtful about the bowel perforation. Due to lack of laparoscopic expertise, decision of laparotomy was taken. On laparotomy it was found that bowel integrity was maintained and no further intervention was needed. Intraperitoneal migration can lead to pain, fibrosis, and adhesion formation and in some situations may result in penetration into adjacent organs including the urinary bladder, sigmoid colon, appendix, and small bowel. ${ }^{16,17}$ It is for this reason it is recommended that surgical exploration and IUCD retrieval should be primary therapeutic approach for patients with such IUD-related complication. ${ }^{16,17}$ If the IUCD has caused perforation of bowel, laparatomy may be needed to remove the IUD and restore the bowel integrity. But, with advances in laparoscopy, such situations are being increasingly managed with minimally invasive techniques. In a case discussed by Zeino MY et al, they laparoscopically removed the IUD that had completely perforated through the colonic wall into the lumen and intracorporeally repaired the resultant colotomy, thus avoiding resecting the colon and avoiding the morbidity of not repairing the colotomy. ${ }^{18}$

Prabhakaran S and Chuang $\mathrm{A}$ in their study even presented with the protocol on how to go about with a patient who presents with missing CuT. In their study, they also used ultrasound as their first investigative modality. $^{15}$

In nutshell, patients presenting with missing $\mathrm{CuT}$ thread mostly have post-partum IUCD. Every case of missing Cooper $\mathrm{T}$ string should be thoroughly investigated to rule out pregnancy and find the position of the CuT. Most of the patients are asymptomatic, however, irregular vaginal bleeding and abdominal pain are commonest symptoms.

TVS should be used as the first investigative modality to confirm the presence of intra uterine CuT. X-ray abdomen erect can be used only if TVS does not demonstrate intrauterine $\mathrm{CuT}$.

CuT can be removed very easily with the help of artery forceps as an office procedure. This is not only more 
convenient but also less costly for the patient and less burden on health care system. However, on failure to remove $\mathrm{CuT}$ with artery forceps, hysteroscopy should be sought to remove the CuT.

In cases of intraperitoneal CuT migration, laparoscopy should be used to remove the CuT. Laparatomy may be needed in cases of lack of laparoscopic expertise.

\section{CONCLUSION}

Missing CuT thread is commonest with postpartum IUCD.TVS should be first investigation in missing CuT thread. X-ray abdomen is needed only if $\mathrm{CuT}$ is not visualised on TVS. Hysteroscopy can be used in patients where CuT retrieval with artery forceps fails. Laparoscopy and laparotomy may be required in migrated $\mathrm{CuT}$ cases.

\section{ACKNOWLEDGMENTS}

Authors would like to thank all faculty members of department of obstetrics and gynecology for their support.

Funding: No funding sources

Conflict of interest: None declared

Ethical approval: The study was approved by the Institutional Ethics Committee

\section{REFERENCES}

1. Kaneshiro B, Aeby T. Long-term safety, efficacy, and patient acceptability of the intrauterine Cooper T-380A contraceptive device. Int J Women's Health. 2010;2:211-20.

2. Sivin I, Batár I. State-of-the-art of non-hormonal methods of contraception: III. Intrauterine devices. Eur J Contracept. 2010;15(2):96-112.

3. Roke CM. A comparative study of the ease of removal of intrauterine contraceptive devices. Contracept. 1988;37:555-63.

4. Waldron K. Intrauterine devices: insertion and removal: practical procedures. Aust Fam Phys. 1982;11:40-4.

5. Bounds W, Hutt S, Kubba A, Cooper K, Guillebaud J, Newman GB. Randomized comparative study in 217 women of three disposable plastic IUCD thread retrievers. Br J Obstet Gynaecol. 1992;99:915-9.

6. Tugrul S, Yavuzer B, Yildirim G, Kayahan A. The duration of use causes of discontinuation, and problems during removal in women admitted for removal of IUD. Contracept. 2005;71:149-52.
7. Broso PR, Buffetti G. The IUD and uterine perforation. Minerva Ginecol. 1994;46(9):505-9.

8. Brar R, Doddi S, Ramasamy A, Sinha P. A forgotten migrated intrauterine contraceptive device is not always innocent: a case report. Case Rep Med. 2010:2010.

9. Bitterman A, Lefel O, Segev Y, Lavie O. Laparoscopic removal of an intrauterine device following colon perforation. JSLS. 2010;14(3):4568.

10. Mishra S. Tale of the tails, the Missing Postpartum IUCD Strings. The J Obstet Gynecol India. 2017;67(3):202-7.

11. Elahi N, Koukab HH. Daignosis and management of lost intrauterine contraceptive device. J Pak Med Asso. 2002;52(1):18-20.

12. Nowitzi KM, Hoimes ML, Chen B, Zheng LZ, Kim YH. Ultrasonography. Korean Society Ultrasound Medi. 2015;34(3):183-94.

13. Marchi NM, Castro S, Hidalgo MM, Hidalgo C, Monteiro-Dantas C, Villarroeal $\mathrm{M}$, et al. Management of missing strings in users of intrauterine contraceptives. Contraception. 2012;86(4):354-8.

14. Berger-Kulemann V, Einspieler H, Hachemian N, Prayer D, Trattnig S, Weber M, et al. Magnetic field interactions of Cooper-containing intrauterine devices in 30-Tesla magnetic resonance imaging: In vivo study. Korean J Radiol. 2013;14:416-22.

15. Prabhakaran S, Chuang A. In office retrieval of Intrauterine contraceptive devices with missing strings. Contracept. 2011;83(2):102-6.

16. Mederos R, Humaran L, Minervini D. Surgical removal of an intrauterine device perforating the sigmoid colon: A case report. Int J Surg. 2008;6:602.

17. Chi E, Rosenfeld D, Sokol TP. Laparoscopic removal of an intrauterine device perforating the sigmoid colon: A case report and review of the literature. Am Surg. 2005;71:1055-7.

18. Zeino MY, Wietfeldt ED, Advani V, Ahad S, Younkin C, Hassan I. Laparoscopic removal of a copper intrauterine device from the sigmoid colon. JSLS: J Soci Laparoendo Surg. 2011;15(4):568-70.

Cite this article as: Junnare KK, Savaskar S, Shekhawat GS. Stings of the missing string: missing Copper T thread. Int J Reprod Contracept Obstet Gynecol 2020;9:99-103. 